\title{
A novel mutation of coproporphyrinogen oxidase (CPO) gene in a Japanese family
}

\begin{abstract}
Hereditary coproporphyria (HCP) is an autosomal dominant disease characterized by a deficiency of coproporphyrinogen oxidase (CPO). Only 11 mutations of the gene have been reported to date as the mutations responsible for HCP. We report here a novel mutation of the gene responsible for the disease in a Japanese family. Analysis of the polymerase chain reaction (PCR) amplified DNA fragments of the gene by direct-sequencing and/or cloning-based sequencing methods revealed the gene abnormality responsible for the disease. The mutation found was a single base deletion of $\mathrm{T}$ at $\mathrm{nt}$ position 526, which results in frame shift and truncation of coded protein at amino acid position 204. Screening of pre-symptomatic cases seemed to be possible by PCR restriction analysis using restriction enzyme $X \mathrm{~cm}$ I.
\end{abstract}

Key words Hereditary coproporphyria $\cdot$ Coproporphyrinogen oxidase $\cdot$ Gene mutation $\cdot$ Single base deletion $\cdot$ Frame shift

\section{Introduction}

Coproporphyrinogen IX oxidase (CPO) [EC 1.3.3.3.] catalyzes the sixth step in heme-biosynthesis (Kappas et al. 1989; Elder et al. 1978). This enzyme activity is reduced to $50 \%$ of normal in tissues of patients with hereditary

S. Susa $\cdot$ M. Daimon $(\bowtie) \cdot$ K. Yamatani $\cdot$ H. Sasaki $\cdot$ T. Kato

Third Department of Internal Medicine, Yamagata University School of Medicine, 2-2-2 Iida-Nishi, Yamagata 990-9585 Japan

Tel. +81-23-628-5316; Fax +81-23-628-5318

e-mail: mdaimon@med.id.yamagata-u.ac.jp

I. Yamamori

Division of Internal Medicine, Japan Red Cross Nagoya First

Hospital, Nagoya, Japan

M. Kondo

Division of Nutrition and Biochemistry, Institute of Public Health,

Tokyo, Japan coproporphyria (HCP), which is an autosomal dominant disease characterized by attacks of abdominal pain, neurological disturbances, and psychiatric symptoms (Kappas et al. 1989). The symptoms are generally manifested with rapid onset, and can be precipitated by drugs, alcohol, caloric deprivation, infection, endocrine factors, or stress (Kappas et al. 1989). Therefore, early detection of carriers of the defective gene is important for the prevention of attacks, since carriers can be advised to avoid the precipitating factors. The most reliable examination for the diagnosis of HCP is to identify the gene abnormality. To date, 11 different mutations have been reported (Delfau-Larue et al. 1994; Martasek et al. 1994; Fujita et al. 1994; Lamoril et al. 1995; Lamoril et al. 1997; Daimon et al. 1997; Schreiber et al. 1997). Here, we report a novel mutation of the gene in a Japanese family.

\section{Materials and methods}

Patient's history and laboratory findings

The patient is a 25-year-old Japanese woman. She was diagnosed as having HCP at age 15 years. Her diagnosis was established on the basis of clinical symptoms, and increased excretion of 8-aminolevulinic acid (ALA) $(8.47 \mu \mathrm{g} / \mathrm{ml}$; nor$\mathrm{mal}, 1.17+0.05)$ and porphobilinogen (PBG) $(6.73 \mu \mathrm{g} / \mathrm{ml}$; normal, $<0.8)$ in urine, and coproporphyrin III $(\mathrm{CP})$ in feces $(3359.0 \mu \mathrm{g} / \mathrm{g}$ dry weight; normal, $4-15)$ and urine $(1260.0 \mu \mathrm{g} / \mathrm{l}$; normal, $34.0+21.0)$. Protoporphyrin in feces was about normal (22.2 $\mu \mathrm{g} / \mathrm{g}$ dry weight; normal, 5-20). Her father and mother were also examined. Her father has never shown clinical symptoms corresponding to the disease but showed a large amount of excretion of porphyrin products, especially in feces (coproporphyrin III, $668.0 \mu \mathrm{g} / \mathrm{g}$ dry weight), while her mother did not. This result indicated that he had latent disease. The family live in Aichi Prefecture of Japan. Genomic DNA was extracted from peripheral blood leukocytes of these members of the family, as described by Sambrook et al. (1989). 


\section{Experimental procedures}

PCR-single strand conformation polymorphism (SSCP) analyses were carried out as reported previously (Daimon et al. 1997). The primers used were made to cover all genomic DNA regions corresponding to the coding region of the cDNA. For each PCR product, all samples were run side-by-side to facilitate comparison of the banding patterns. The nucleotide sequences of the amplified DNA fragments, which showed a unique banding pattern, were determined by dideoxy sequencing. The mutation found can be detected by restriction analysis of the PCR products. The DNA fragment containing the mutation site was amplified by PCR, using the primers E1F2 (5'CGGGCGGAGATGTTGCCTAAGAC- $3^{\prime}$ ) and E1R2 (5'-CCCCATCCCATA TTGTGAACTAT- $\left.3^{\prime}\right)$. The mutation abolishes a restriction enzyme $X \mathrm{~cm}$ I recognition site $\left(5^{\prime}\right.$-CCANNNNN/NNNNTGG-3') in the 364-bp PCR product from the normal allele. Therefore, the PCR product from the normal allele is cut into 237-bp and 127-bp fragments, but that derived from the mutant allele (363 bp in length) is not. The PCR products were electrophoresed in a $1.5 \%$ agarose gel after digestion with the restriction enzyme (New England BioLabs, Beverly, MA, USA).

\section{Results and discussion}

We used SSCP analysis to screen all exons of the CPO gene for detecting gene mutations. SSCP analysis of the PCR products containing downstream part of the exon 1 of the patient showed a unique banding pattern. The sequencing ladders of the anti-sense strand of the PCR product showed double bands from $\mathrm{T}$ at position 526 from the translation initiation codon proposed by Delfau-Larue et al. (1994), and comparison of this sequence with the normal sequence revealed that one allele (mutant allele) containing a single base deletion of $\mathrm{T}$ presented simultaneously with the normal allele (Fig. 1A). This deletion resulted in a frame shift and truncation of coded protein at amino acid position 204 (Fig. 1B). Thus, the length of the mutated protein is expected to be about half of that of the native protein, which is 454 amino acids (aa), including an 110-aa presequence. Therefore, this mutation appeared to be responsible for the disease of the patient.

Only 11 different mutations of the CPO gene responsible for HCP have been reported to date (Delfau-Larue et al. 1994; Martasek et al. 1994; Fujita et al. 1994; Lamoril et al. 1995; Lamoril et al. 1997; Daimon et al. 1997; Schreiber et al. 1997). Eight of them are single-base substitutions (Fujita
Fig. 1 A Sequencing analysis of the amplified DNA fragment from the hereditary coproporphyria (HCP) patient. Nucleotide sequence ladders around the mutation site of the coproporphyrinogen oxidase $(\mathrm{CPO})$ gene are shown. The position of the mutation is indicated by a circle and arrow. B The predicted result of the protein residues is shown in conjunction with a schematic presentation of normal $\mathrm{CPO}$ protein. The shaded boxes indicate the presequence of the normal protein. The vertical line in the open box indicates the position where the change of amino acid (aa) residues starts. C Restriction analysis of the polymerase chain reaction (PCR) products. The PCR products containing the mutation site were analyzed as described in Materials and Methods. The individuals of the HCP family examined are indicated at the top of the panel. The square and the circles represent the male and the females, respectively. The filled symbol with the arrow represents the patient (propositus). The symbol with the dot represents the individual with a latent case of the disease carrying the abnormal CPO gene. DNA molecular weight standard pHY size marker (Toyobo, Tokyo, Japan) is loaded in lane $M$. The PCR product of a control subject was loaded on lane C. Numbers on the left and right indicate the sizes of DNA size markers and fragments respectively, observed in this analysis
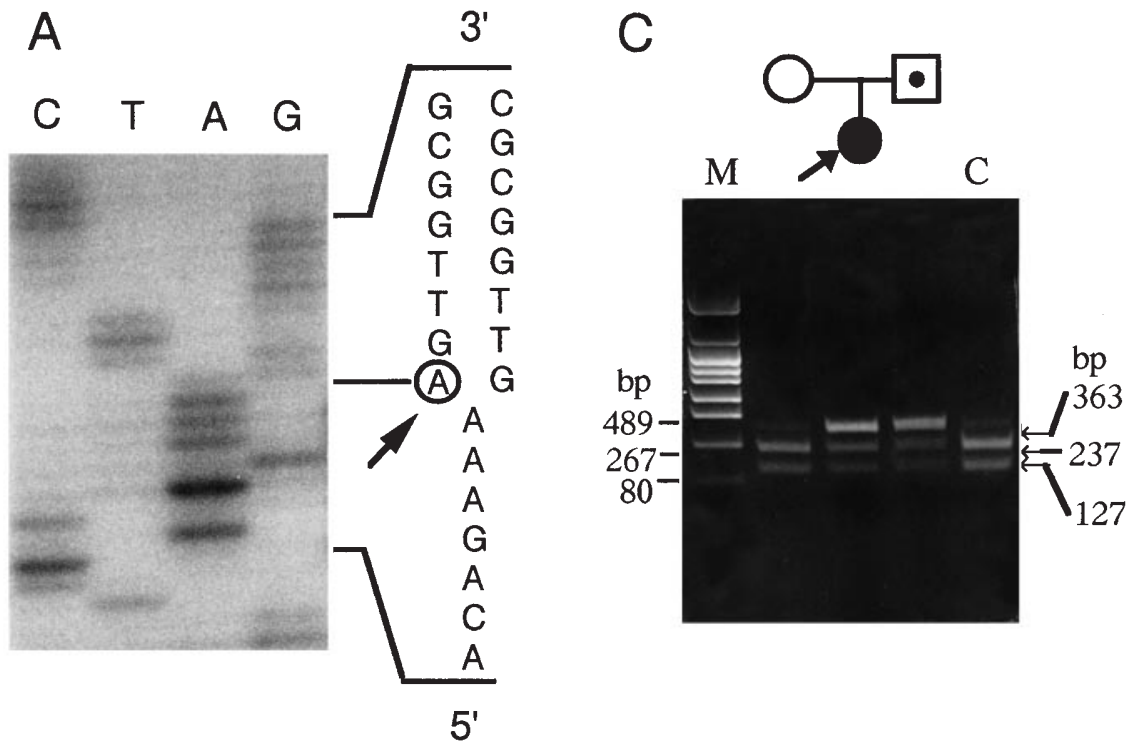

B 1 110 454

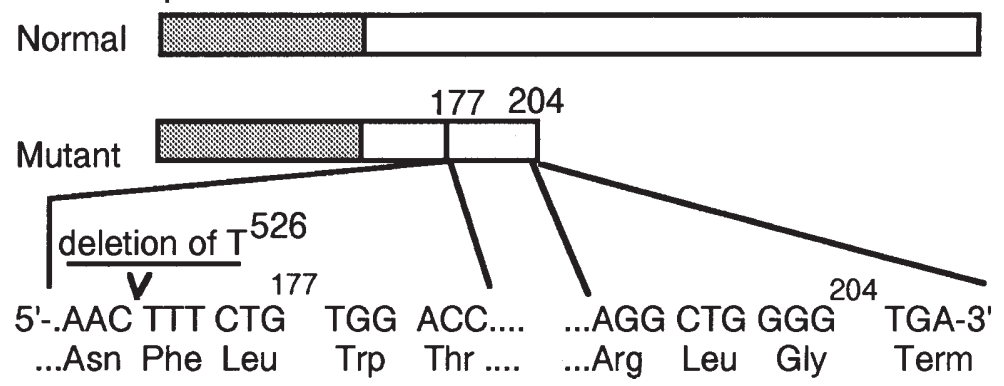


et al. 1994; Martasek et al. 1994; Delfau-Larue et al. 1994; Lamoril et al. 1995; Lamoril et al. 1997; Daimon et al. 1997; Schreiber et al. 1997). Three others are a 5-bp insertion and a 21-bp in-frame deletion in exon 1 (Lamoril et al. 1997), and a one-base pair insertion in exon 6 (Schreiber et al. 1997). The mutation reported here (delT526) is a novel single-base deletion in exon 1.

The PCR restriction analysis revealed that the patient and her father are heterozygotes of the abnormal and mutant alleles, while her mother and a control individual are homozygotes of the normal allele (Fig. 1C). This analysis clearly indicates that the mutant allele is inherited from her father.

It has been reported that different families have different mutations of the CPO gene. Thus, the molecular pathology of HCP seems to be highly heterogeneous, as is known to be the case in acute intermittent porphyria, another form of inherited hepatic acute porphyria.

\section{References}

Daimon M, Gojyou E, Sugawara M, Yamatani K, Tominaga M, Sasaki $\mathrm{H}$ (1997) A novel missense mutation in exon 4 of the human coproporphyrinogen oxidase gene in two patients with hereditary coproporphyria. Hum Genet 99: 199-201
Delfau-Larue MH, Martasek P, Grandchamp B (1994) Coproporphyrinogen oxidase: Gene organization and description of a mutation leading to exon 6 skipping. Hum Mol Genet 3: 1325-1330

Elder GH, Evans JO (1978) Evidence that the coproporphyrinogen oxidase activity of rat liver is situated in the intermembrane space of mitochondria. Biochem J 172: 345-347

Fujita H, Kondo M, Taketani S, Nomura N, Furuyama K, Akagi R, Nagai T, Terajima M, Galbraith RA, Sassa S (1994) Characterization and expression of cDNA encoding coproporphyrinogen oxidase from a patient with hereditary coproporphyria. Hum Mol Genet 3: $1807-1810$

Kappas A, Sassa S, Galbraith RA, Nordmann Y (1989) The porphyrias. In: Stanbury JB, Wyngaarden JB, Fredrickson DS, Goldstein JL, Brown MS (eds) The metabolic basis of inherited disease, 6th edn. McGraw-Hill, New York, pp 1305-1365

Lamoril J, Martasek P, Deybach JC, Da Silva V, Grandchamp B, Nordmann Y (1995) A molecular defect in coproporphyrinogen oxidase gene causing harderoporphyria, a variant form of hereditary coproporphyria. Hum Mol Genet 4: 275-278

Lamoril J, Deybach J-C, Puy H, Grandchamp B, Nordmann Y (1997) Three novel mutations in the coproporphyrinogen oxidase gene. Hum Mut 9: 78-80

Martasek P, Nordmann Y, Grandchamp B (1994) Homozygous hereditary coproporphyria caused by an arginine to tryptophane substitution in coproporphyrinogen oxidase and common intragenic polymorphisms. Hum Mol Genet 3: 477-480

Sambrook J, Fritsch EF, Maniatis T (1989) Molecular cloning - a laboratory manual, 2nd edn. Cold Spring Harbor Laboratory Press, New York

Schreiber WE, Zhang X, Senz J, Jamani A (1997) Hereditary coproporphyria: Exon screening by heteroduplex analysis detects three novel mutations in the coproporphyrinogen oxidase gene. Hum Mutat 10: 196-200 